\title{
Representasi Male Gaze terhadap Perempuan dalam Iklan Dot Dodo
}

\author{
Fajar Mahanani (Penulis Korespondensi) \\ Program Studi Ilmu Komunikasi, Universitas Muhammadiyah Yogyakarta, Indonesia \\ mahananifajar19@gmail.com \\ Safa Aqilla D \\ Program Studi Ilmu Komunikasi, Universitas Muhammadiyah Yogyakarta, Indonesia \\ safaaqilladevanti@gmail.com \\ Salsabiela Aurelia P. B \\ Program Studi Ilmu Komunikasi, Universitas Muhammadiyah Yogyakarta, Indonesia \\ salsabiela2000@yahoo.com \\ Diserahkan: 08 Mei 2020; Direvisi: 06 Oktober 2020; Diterima: 10 Oktober 2020
}

\begin{abstract}
In an advertisement, women are often becoming the object of exploitation. The woman in sexy clothes and the camera spotlight that focuses on curves and gestures make the ad more attractive to the audience, as well as in the Dot Dodo ad. The purpose of this research is to see how the male gaze representation in Dot Dodo advertisement takes place. This study uses a semiotic method to analyze the object of research in the form of a 2013 street version of Dot Dodo advertisement with a 29-second video. The object of this study was analyzed using Roland Barthes' semiotic analysis, which developed the thinking of Ferdinand De Saussure. The analysis is carried out through the signs that appear from snippets of scenes taken in the Dot Dodo advertisement starting from the expressions, gestures, and monologues or sentences used. The results showed that the male camera representation of women is very dominant. In this case, women are accidentally required to appear perfect in advertising media with their body shape.

Keywords: Dot Dodo Ads, Male Gaze, Women, Representation
\end{abstract}

\section{Abstrak}

Di dalam sebuah iklan, perempuan sering kali dijadikan objek eksploitasi. Perempuan dengan pakaian seksi serta sorotan kamera yang fokus pada lekuk dan gerak tubuh seakan membuat iklan lebih menarik khalayak, begitu juga dalam iklan Dot Dodo. Tujuan dari penelitian ini adalah untuk mengetahui bagaimana representasi tatapan laki-laki (male gaze) dalam Iklan Dot Dodo berlangsung. Penelitian ini menggunakan metode semiotika untuk menganalisis objek penelitian berupa iklan Dot Dodo versi jalan-jalan tahun 2013 dengan video berdurasi 29 detik. Objek penelitian ini dianalisis dengan menggunakan analisis semiotika Roland Barthes yang mengembangkan pemikiran dari Ferdinand De Saussure. Analisis yang dilakukan yaitu melalui tanda yang muncul dari cuplikan adegan-adegan yang diambil dalam Iklan Dot Dodo mulai dari ekspresi, gerak tubuh, maupun monolog atau kalimat yang digunakan. Hasil penelitian menunjukkan bahwa representasi male gaze camera terhadap perempuan sangatlah dominan. Dalam hal ini, secara tidak sengaja, perempuan dituntut untuk tampil sempurna dalam media iklan dengan bentuk tubuhnya.

Kata Kunci: Iklan Dot Dodo, Male Gaze, Perempuan, Representasi

\section{PENDAHULUAN}

Iklan merupakan sebuah bentuk komunikasi di mana di dalamnya terdapat berbagai macam tanda untuk mengkomunikasikan produk atau jasa yang ditawarkan (Wicaksono, 2012). Dalam kehidupan sehari-hari kita tidak dapat dipisahkan dengan iklan. Iklan merupakan bentuk komunikasi yang ditujukan guna menarik perhatian konsumen agar tertarik membeli dan menggunakan produk atau jasa yang ditawarkan. Secara sadar atau tidak sadar iklan sering kita temui, baik iklan di televisi, sosial media, koran, majalah, radio, ataupun iklan luar griya.

Adanya sebuah persaingan menuntut pengiklan menggali ide yang lebih kreatif untuk menarik perhatian target market-nya. Penggunaan diksi yang unik merupakan bagian dari upaya kreatif pengiklan untuk menarik perhatian target market-nya, namun terkadang secara sengaja pemilihan diksi tersebut 
mengandung unsur eksploitasi (Wicaksono,2012). Dalam hal ini, iklan kerap kali mengundang kontroversi, baik dari pemeran hingga jingle iklannya. Kebanyakan iklan memilih perempuan sebagai objeknya. Perempuan dinilai lebih mampu memikat dan menarik perhatian khalayak. Penempatan gender dalam iklan juga menjadi perbincangan hangat. Tak sedikit iklan yang menjadikan gender, terutama perempuan, sebagai penguat merek produk atau jasa pengiklan. Dalam hal ini, perempuan dalam iklan televisi seakan hanya dijadikan daya tarik agar menarik perhatian khalayak dan dapat meraup keuntungan bagi pengiklannya.

Umumnya kritik terhadap iklan kaitannya dengan representasi perempuan berhubungan pada tiga hal (1) Adanya stereotip bahwa perempuan menjadi pemain yang pasif dan kurang kuat di dalam masyarakat; (2) Penggambaran perempuan sebagai objek seksual dalam iklan, dan; (3) Efek kumulatif dari penggambaran tentang harga diri perempuan (Frith dalam Wicaksono, 2012). Perempuan menjadi objek atas kekuasaan laki-laki yang seolah-olah mempunyai peran dominan disektor publik. Hal ini terlihat pada perempuan dalam iklan televisi yang pada program acara sehari-hari. Dalam konteks ini, perempuan hanya dijadikan objek untuk meraup keuntungan tanpa memikirkan harga diri perempuan itu sendiri.

Tujuan dari penelitian ini adalah untuk mengetahui bagaimana representasi tatapan laki-laki (male gaze) dalam Iklan Dot Dodo berlangsung. Iklan Dot Dodo ini menjadi objek penelitian karena iklan tersebut memunculkan model- model perempuan yang bertemu dengan seorang anak kecil atau balita. Sekilas, perempuan dalam iklan Dot Dodo menjadi objek yang paling menonjol, karena setiap adegan selalu menyorot dada dan payudara perempuan. Dalam pandangan penulis, hal ini sangat memprihatinkan dan dinilai kurang patut untuk iklan anak-anak. Penelitian terdahulu menyebutkan bahwa, bentuk praktik-praktik eksploitasi yang terjadi kepada perempuan dapat dibedakan menjadi 3 hal yaitu (1) Komodifikasi tubuh perempuan dalam televisi sebagai barang dagangan yang dinilai tinggi; (2) Adanya kekerasan simbolik yang menjurus pada dijadikannya tubuh perempuan sebagai sensual pleasure laki-laki; (3) Adanya obesesi-obsesi tubuh langsing dan ramping yang dimanfaatkan oleh bisnis kecantikan (Sukmono, 2015).

\section{KERANGKA TEORI}

\section{SEMIOTIKA}

Semiotika berasal dari bahasa Yunani yakni semieon yang berarti tanda. Semiotika diperkenalkan oleh Ferdinand De Saussure (1857-1913). Semiotika berangkat dari kajian tentang tanda (sign) yang terdiri dari dua aspek, yaitu penanda (signifier), dan petanda (signified). Penanda bisa dipahami sebagai bentuk atau wujud fisik, seperti audio, gambar, visual, dan sejenisnya. Sedangkan petanda ialah konsep atau arti dari apa yang ditandai. Hubungan antara keduanya bersifat "diada-adakan" (arbitrary), yakni tidak ada hubungan bersifat alamiah antara penanda dan petanda. Meski demikian, hubungan yang bersifat "diada-adakan" tersebut terikat oleh konvensi atau struktur.

Pemikiran Ferdinand De Saussure kemudian dikembangkan oleh Roland Barthes dengan memberi telaah dalam interaksi antara teks dengan pengalaman personal dan kultural penggunanya. Interaksi antara konvensi dalam teks dengan konvensi yang dialami dan diharapkan oleh penggunanya dikenal dengan tatanan penandaan (order of signification). Gagasan Roland Barthes tersebut mencakup primary signification atau denotasi (makna sebenarnya sesuai kamus) dan secondary signification atau konotasi (makna ganda yang lahir dari pengalaman kultural dan personal). Makna konotasi inilah yang kemudian berkembang menjadi mitos. Dalam penelitian ini, penulis berusaha melakukan analisis semiotika, mulai dari primary signification sampai secondary signification pada iklan WRP versi Limited Edition. 


\begin{tabular}{c|c}
\hline $\begin{array}{c}\text { Signifier } \\
\text { (Penanda) }\end{array}$ & $\begin{array}{c}\text { Signified } \\
\text { (Petanda) }\end{array}$ \\
\hline \multicolumn{2}{c}{$\begin{array}{c}\text { Denotatif Sign } \\
\text { (Tanda Denotatif) }\end{array}$} \\
$\begin{array}{c}\text { Connotatif Signifier } \\
\text { (Penanda Konotatif) }\end{array}$ \\
\multicolumn{2}{c}{$\begin{array}{c}\text { Connotatif Signified } \\
\text { (Petanda Konotatif) }\end{array}$} \\
\hline \multicolumn{2}{c}{ (Tanda Konotatif) }
\end{tabular}

Gambar 1. Pemaknaan tanda dalam semiotika Roland Barthes (Sobur, 2004)

\section{REPRESENTASI}

Iklan diciptakan dan disebarluaskan oleh produsen dengan tujuan memberikan informasi maupun mendorong masyarakat untuk mengkonsumsi produk-produk tertentu agar sirkulasi kapital berputar semakin cepat. Disinilah proses komodifikasi dan domestikasi perempuan dimulai untuk kepentingan akumulasi kapital sebesar-besarnya. Di saat yang bersamaan, budaya konsumerisme tumbuh dan berkembang (Zamroni, 2007). Tak hanya itu, iklan juga seringkali menjadikan tubuh perempuan (estetika, gairah, sensualitas, erotisme) sebagai pusat perhatiannya, meskipun acara/iklan tersebut tidak mempromosikan suatu produk fashion tertentu (Sukmono, 2015). Penggunaan unsur seksualitas dalam iklan seakan-akan mempunyai mitos yang dipercaya terkandung muatan ideologi tersembunyi dan diyakini dapat memengaruhi dan menciptakan pemahaman di benak khalayak mengenai pesan dan produk yang diiklankan (Pah, 2018).

Representasi adalah proses sosial yang masuk dalam semua sistem penandaan yang tersedia seperti pidato, penulisan, cetak, video, film, kaset, dan sebagainya. Representasi sendiri merupakan konstruksi budaya. Dalam hal ini, representasi secara intrinsik terikat dengan proses seleksi. Kritik feminis dalam melihat representasi perempuan adalah bahwa sering kali representasi merendahkan perempuan dan mempromosikan kekerasan terhadap perempuan. Kerap kali perempuan menjadi objek dalam iklan di televisi. Dengan berpakaian seksi atau menyorot gerak tubuh perempuan seakan membuat iklan lebih menarik, padahal justru merendahkan perempuan. Faktanya, perempuan hanya dijadikan objek untuk meraup keuntungan.

Kekuatan representasi sendiri terletak pada kemampuan untuk memunculkan beberapa jenis pengetahuan dengan mengecualikan cara pandang lainnya. Ketika seseorang bertanya tentang apa artinya menjadi pria, wanita, muda, tua, hitam, putih, gay, lurus (straight), maka saat itu kita terlibat dalam politik representasi. Sebagai contoh, identitas orang kulit hitam tidak mencerminkan keberadaan yang esensial melainkan identitas yang harus diwakili dan dipelajari. Hall berpendapat bahwa politik representasi pada dasarnya berusaha untuk menanyakan hubungan kekuasaan yang melekat yang secara bersamaan mendekonstruksi syarat-syarat biner hitam-putih (Barker, 2004). Representasi bergantung pada tanda dan gambar yang ada dan dipahami secara budaya, pada timbal balik bahasa yang dipelajari, dan berbagai sistem penandaan atau tekstual (Hartley, 2004).

\section{MALE GAZE DAN GENDER}

Male gaze dalam teori feminis adalah tindakan memandang representasi perempuan yang mengungkapkan informasi tentang hubungan kekuasaan yang ada antara pria dan wanita. Dalam masyarakat Barat, para pengamat biasanya adalah laki-laki yang menatap perempuan. Pola ini tampak jelas dalam penggambaran seni dan erotisme yang menjadi ciri sejarah representasi visual Barat. Mengikuti munculnya teori feminisme dan gender, pola memandang sudah mulai berubah secara radikal (Danesi, 2009). 
Butler mengeksplorasi konsep gender tidak seperti yang tampak sebagai alami atau fenomena biologis, tetapi sebagai kinerja yang dibentuk secara sosial dan budaya. Hal tersebut mengingatkan kita pada perbedaan mendasar antara seks dan gender. Seks adalah hasil dari alam (kita dilahirkan laki-laki atau perempuan) sementara gender adalah hasil dari budaya dan masyarakat (kita tumbuh sesuai dengan norma maskulin atau feminin). Dalam hal ini, media massa memainkan peran penting dalam merepresentasikan gender. (Laughley, 2007).

Saat ini gender telah menjadi wacana sosial yang mempersepsikan berbagai manifestasi peran laki-laki dan perempuan dalam menata hubungan sosialnya. Meskipun demikian, pemahaman tentang gender belumlah mencapai suatu bentuk konstruksi sosial yang dapat memuaskan berbagai pihak, mengingat terdapat berbagai macam tafsiran dalam ideologi gender itu sendiri. Hal yang perlu dicatat adalah pemahaman gender perlu dikaitkan dengan budaya masyarakat dalam menata hubungan antara laki-laki dan perempuan dalam berbagai peran dan kegiatannya (Suasana, 2001).

Identitas seksual gender dibangun dalam konteks budaya. Misalnya, dalam masyarakat Barat, laki-laki sering digambarkan sebagai "pencari seks," menunjukkan minat agresif dalam seks sebagai bagian dari identitas gender mereka, dan perempuan sebagai target minat mereka. Dalam budaya lain, seperti beberapa tradisi penduduk asli Amerika, minat tersebut dilihat sebagai bagian dari identitas gender perempuan (Danesi, 2009)

\section{METODE PENELITIAN}

Penelitian ini adalah penelitian deskriptif kualitatif dengan paradigma kritis. Secara lebih operasional, penelitian ini menggunakan metode semiotika untuk menganalisis objek penelitian berupa iklan Dot Dodo versi jalan-jalan tahun 2013 dengan video berdurasi 29 detik. Objek penelitian tersebut dianalisis dengan menggunakan analisis semiotika Roland Barthes.

\section{HASIL DAN PEMBAHASAN \\ REPRESENTASI SEKSUALITAS TUBUH PEREMPUAN}

Perempuan yang dinilai cantik oleh budaya pop selalu diidentikkan dengan kulit putih, berambut lurus dan panjang, bertubuh sintal, dan berpakaian seksi mengikuti lekuk-lekuk tubuh. Adapun untuk laki-laki, dinilai macho apabila memiliki wajah yang tampan, tubuh proporsional atau atletis dengan lekukan dada dan perut yang six pack. Shimp (2003) menjelaskan bahwa daya tarik seksual mempunyai peran-peran potensial. Pertama, materi seksual pada iklan bertindak sebagai daya tarik perhatian sekaligus mempertahankan perhatian untuk waktu lebih lama sering kali ditunjukkan dengan model yang menarik dengan pose merangsang. Peran potensial kedua adalah meningkatkan ingatan terhadap pesan. Riset menunjukkan bahwa iklan berdaya tarik seksual dapat meningkatkan ingatan apabila sesuai dengan kategori produk dan pelaksanaan kreatif iklan. Daya tarik seksual menghasilkan ingatan yang lebih baik apabila pelaksanaan periklanan mempunyai hubungan yang tepat dengan produk yang diiklankan. Adapun peran ketiga ialah membangkitkan tanggapan emosional seperti perasaan arousal (merangsang) atau nafsu. Reaksi-reaksi tersebut dapat meningkatkan pengaruh persuasif iklan begitu juga sebaliknya dapat menimbulkan perasaan negatif seperti rasa jijik, rasa malu, atau perasaan tidak senang (Pah, 2018). 


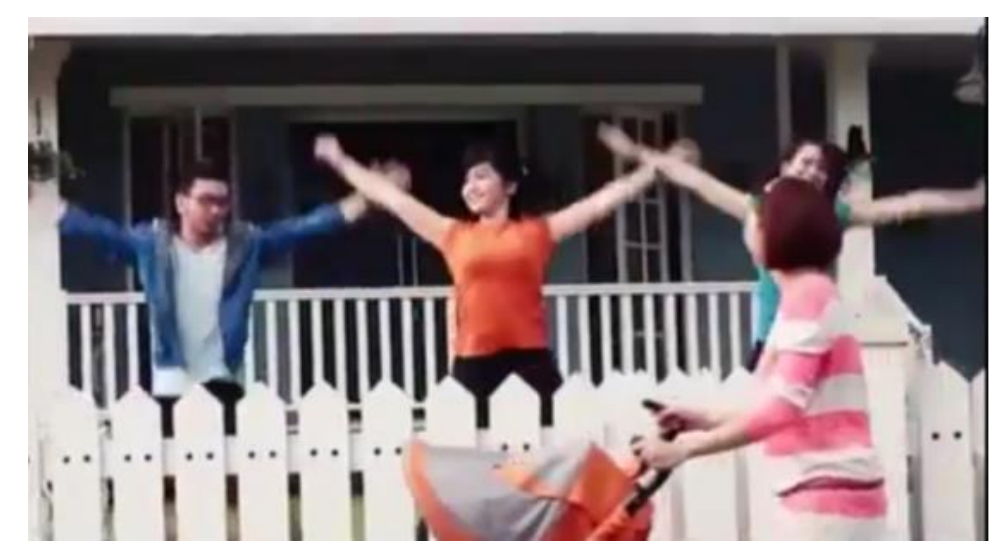

Gambar 2. Adegan perempuan senam dalam iklan Dot Dodo (Youtube, 2020)

Analisis semiotika yang diambil melalui screen shot pada gambar 2 mempunyai tanda dan makna tersendiri. Terlihat dua orang perempuan dan satu laki-laki sedang melakukan senam. Namun demikian terdapat hal yang janggal yaitu sorotan mata laki-laki yang melihat payudara wanita yang berada di sampingnya. Dalam hal ini, perempuan dijadikan bahan tontonan pada saat salah satu bagian tubuhnya menonjol.

Adapun makna konotasi yang muncul dari adegan tersebut adalah perempuan menggunakan pakaian ketat dan terlihat sensual saat senam. Pakaian ketat yang digunakan perempuan sering menjadi objek pandangan laki-laki. Dalam hal ini tubuh perempuan yang disorot menjadi objek seksualitas pemuas laki-laki.

\section{REPRESENTASI FETISISME TUBUH PEREMPUAN}

Representasi tubuh perempuan di dalam masyarakat hampir selalu berada di tangan laki-laki. Dalam dirinya sendiri, bentuk perempuan biasanya telah digambarkan sebagai entitas ideal fantasi laki-laki, ditatap dan diinginkan. Tubuh diberikan makna-makna tertentu yang secara kultural semata-mata hanya sebagai seks (Meutia \& Dwiningtyas, 2016).

Dalam dunia periklanan, fetisisme digunakan pada sebuah produk yang dicitrakan sedemikian rupa sehingga menjadi simbol dan tidak sekedar bernilai guna tapi juga membawa konotasi (Trismaya, 2015). Fetisisme telah mengubah perempuan menjadi citra yang aman, dapat dinikmati, dan tidak mengancam dengan mengubah beberapa bagian tubuhnya menjadi fetis yaitu dengan memusatkan perhatian pada beberapa aspek perempuan yang dibuat menyenangkan (Ayun, 2015).

Menurut Burton (2000) adanya fetisisme tubuh perempuan diantaranya terletak pada bagian payudara. Hal tersebut dapat dilihat dari sejumlah iklan yang mengksploitasi bagian payudara. Gagasan tentang fetisisme tubuh mempunyai dua definisi utama, salah satunya adalah psycho analysis, di mana beberapa bagian dari tubuh menjadi suatu objek yang mewakili seksualitas. Dalam istilah representasi, tubuh berkedudukan sebagai image dan identitas, sehingga orang hanya fokus pada tubuh bukan pada kualitas personal (Meutia \& Dwiningtyas, 2016). Berikut adalah dua potongan gambar yang menunjukkan bagaimana unsur fetisisme ditampilkan dalam iklan Dot Dodo. 


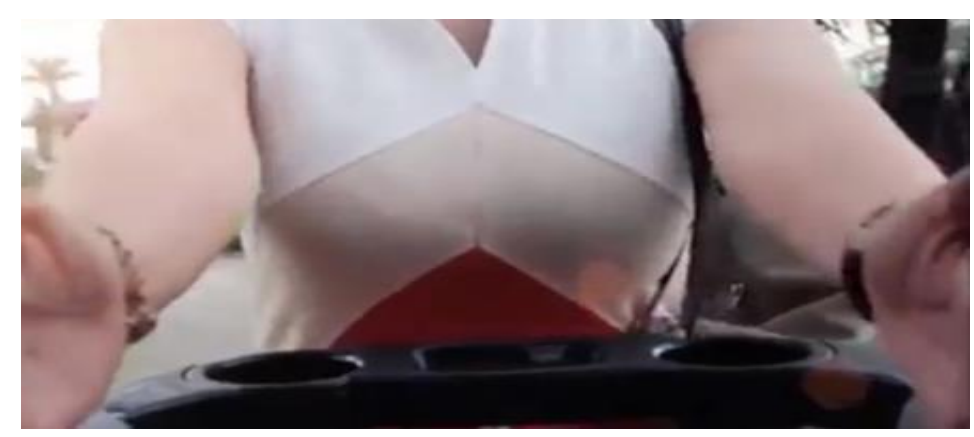

Gambar 3. Scene objek perempuan mendekati anak kecil di kereta bayi (Youtube, 2020).

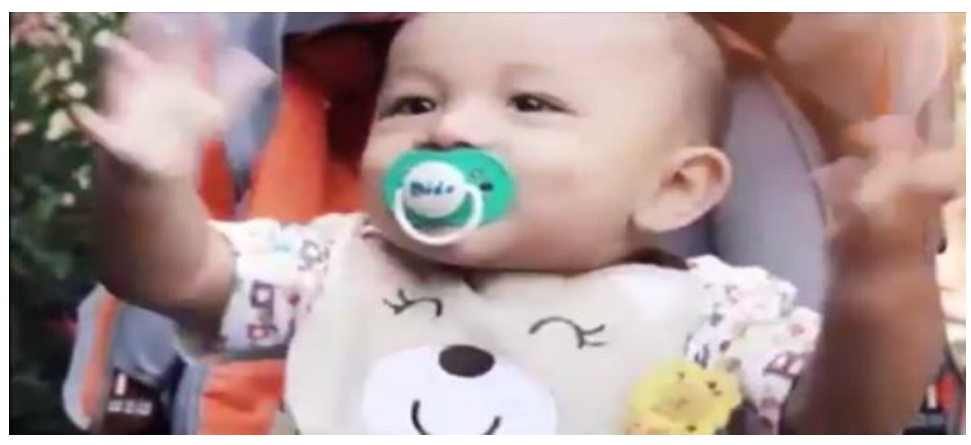

Gambar 4. Scene anak kecil yang tertawa melihat objek perempuan mendekatinya (Youtube, 2020).

Apabila dianalisis secara cermat, makna konotasi yang muncul adalah bahwa design dot merek Dodo terinspirasi dari puting susu ibu. Screenshot pada iklan gambar 3 menampilkan makna bahwa perempuan seksi yang ditampilkan mempunyai puting susu yang sama rasanya dengan dot padahal tidak semua perempuan seksi memiliki puting susu atau payudara yang sama rasanya dengan dot.

Adapun analisis semiotika pada objek tubuh perempuan yang menyoroti bagian payudara tersebut memiliki tanda dan makna tersendiri. Penanda yang berbentuk pada gambar 4 yaitu saat anak kecil tersebut tertawa dan senang saat melihat seorang perempuan yang mendekatinya. Namun demikian, sang anak fokus melihat payudara perempuan tersebut yang dirasa sama rasanya saat menikmati puting susu ibu.

Sebagai sebuah produk yang digunakan oleh bayi berumur kurang dari 5 tahun, konten iklan seharusnya tidak perlu menampilkan model wanita seksi sebagai bintang iklannya karena gerakan dan penampilan model yang ditampilkan sangatlah seronok. Dalam pandangan penulis, dapat dikatakan bahwa perempuan dalam ikan Dot Dodo hanya merupakan objek seks yang dilihat dan dinikmati lakilaki.

\section{KESIMPULAN}

Dari hasil analisis yang dilakukan, setidaknya terdapat beberapa gambaran bagaimana perempuan diperlakukan dan diletakkan pada tanda dan citra tertentu. Dalam hal ini, perempuan hanya dimanfaatkan oleh pengiklan untuk memenuhi kebutuhannya. Representasi male gaze terhadap perempuan sangatlah dominan. Secara tidak sengaja, perempuan dituntut untuk tampil sempurna dalam media dengan bentuk tubuhnya. Segala sesuatu yang dibentuk oleh media saat ini membuat 
perempuan menganggap bahwa kesempurnaan bentuk tubuh adalah bentuk tubuh yang ditampilkan di media massa, di luar itu dianggap buruk. Media telah merepresentasikan perempuan yang identic dengan kulit yang putih, berambut lurus dan panjang, bertubuh sintal, hingga berpakaian seksi mengikuti lekuk-lekuk tubuhnya. Perempuan diletakkan sebagai daya tarik untuk menarik perhatian sekaligus mempertahankan perhatian tersebut dalam waktu lebih lama.

\section{PERSANTUNAN}

Terima kasih kepada Dr. Fajar Junaedi yang telah membimbing proses riset dalam mata kuliah Kajian Kritis Iklan di Program Studi Ilmu Komunikasi UMY, selama satu semester genap tahun akademik 2019/2020 yang menghasilkan luaran berupa artikel ini.

\section{REFERENSI}

Ayun, P. Q. (2015). Sensualitas dan Tubuh Perempuan dalam Film-film Horor di Indonesia (Kajian Ekonomi Politik Media). Jurnal Simbolika, 1(1), 16-22.

Barker, Chris. (2004). The SAGE Dictionary of Cultural Studies. London: SAGE Publications.

Danesi, M. (2009). Dictionary of Media and Communications. Inggris: M.E.Sharpe. Fiske, J. (1994). Key Concepts in Communication and Cultural Studies. London: Routledge.

Fitryarini, I. (2009). Iklan dan Budaya Popular: Pembentukan Identitas Ideologis Kecantikan Perempuan oleh Iklan di Televisi. Jurnal Ilmu Komunikasi, 6(2), 119-136.

Hartley, J. (2004). Communication, Cultural, and Media Studies: The Key Concepts. London: Routledge. Juditha, C. (2015). Gender dan Seksualitas dalam Konstruksi Media Massa. Jurnal simbolika, 1(1), 6-14. Laughey, D. (2007). Key Themes in Media Theory. England: Open University Press.

Rachma, F. M. (2016). Seksualitas Tubuh Perempuan dalam Film Biografi Tentang Bintang Porno Lovelace. Interaksi Online, 4(3), 1-10.

Pah, J. J. (2018). Mitos Seksualitas dalam Iklan. Nyimak Journal of Communication. 2(1), 1-16.

Suasana, A. A. (2004). Hubungan Gender dalam Representasi Iklan Televisi. Nirmana, 3(1), 1-16.

Sukmono, B. (2015). Eksploitasi Tubuh Perempuan di Televisi Sebagai Ironi Kepribadian Indonesia. Komunikator, 4(1), 14-15.

Trismaya, N. (2015). Tubuh Wanita dalam Ranah Mode sebuah Tinjauan Fetis Seksual dan Komoditi. Jurnal STDI, 8(15), 666-673.

Wicaksono, I. P. (2012). Representasi Eksploitasi Perempuan dalam Iklan. Jurnal Ilmu Komunikasi, 9 (2), 149-167.

Zamroni, M. I. (2007). Kapitalisasi Tubuh Perempuan dalam Iklan Televisi. Jurnal Ilmu Komunikasi, 2(1), 287.296. 